\title{
Conference Report: The Internet as Playground and Fac- tory (November 12-14, 2009, The New School, New York City, USA)
}

\author{
David Golumbia
}

University of Virginia, http://www.engl.virginia.edu/faculty/golumbia_david.shtml, dgolumbia@gmail.com

ove hristian Fuchs provided an excellent overview of the methods and themes in evidence at the Playbor conference in his recent review (Fuchs, 2009). Here I want to stand back and make some observations about the functions of the kinds of work done at the conference, the role of academic inquiry in the construction of media, and the possible uses of critical studies in the world of practice. More than that, I want to draw our attention to a potentially groundbreaking change in the functions of critical theory and even academic inquiry.

I will admit to being very surprised by this conference. Like many, it turns out, I felt the original theme of the conference was a bit "light". This is by no means to fault the organizers; it's a subject that many people have been talking about, and that many of us have a lot to say about; it's just that the basic questions appear to come mostly out of commercial software products (Facebook, Twitter, World of Warcraft), which few of us in critical studies of the digital world consider particularly transformational, even in the long history of ICTs. But as the frequently contentious discussion on the IDC list preceding the conference showed, it helped to define a fault line in our thinking and theorizing that ultimately proved electrifying.

I have been at many conferences in my life, but I have never been at one like this. My impression was not of academics trying to hone their theory to fit the latest facts, although some of that went on. My impression was of close to 1000 incredibly smart people, mostly but not all academics, from a variety of backgrounds, experiences, methodologies and orientations, trying to stand with as much critical distance as possible from what is per- haps the definitive technological and media change of recent times, trying to frame it in terms of the historical, cultural, and geographical changes on top of which it lays, and trying to understand what is happening and why it is happening as it happens.

As much as the Frankfurt school critics, and later the critical theorists of the late $20^{\text {th }}$ century, engaged profoundly with every media form of their time, something about this conference struck me quite differently. Because of the distributed nature of ICTs, we all come to the subject with different levels of technical skill and even production commitments in the very medium we are discussing. This is new: we are closer to our object of study, without necessarily being enmeshed in its corporate sites of production, than we could have been in radio, television, movies, and even earlier regimes of ICTs. This is in part exactly the reason that we are wondering whether "social technologies" like web 2.0 can distribute skill and understanding more widely than they can have been before.

This struck me most forcefully at the conference's closing panel discussion. My sense was that a body of knowledge - a knowledge of how dramatic, how forceful, and how ideological have been the historical conditions out of which our contemporary moment emerged, perhaps summarized most forcefully by Jon Beller's invocation of the Armageddon that about $2 / 3$ of the world has experienced as "we" have created the world of IT - was coming into direct contact with a practice, namely the computerization of the world. That very fact is different from the printing press, the telegraph, the railroad, radio, tv, and film. At the panel Trebor Scholz mentioned that employees from Yahoo, Microsoft and Google 
appeared to have attended the conference, though none of them agreed to speak. This seemed just right. The knowledge contained in that room was too well-earned to be dismissed by the commercial powers that largely run our world; the possibility that we do have some sort of technical purchase from which to effect real change, again, very close to the subject of the conference, seemed to come to the fore again. Perhaps in that room, we understood that technologies almost never, of themselves, produce positive social change; that when we are sold a story that some particular communication technology and its distribution (as has been done with every prior technology - and can it possibly be different this time?) will change the world, too often in the past that story has concealed very much the opposite. Yet very few of us were willing to reject the idea, as one question put it toward the very end, that "there really might be something different about information technology."

Is there? We can't know, unless and until "it" happens, until we see mass-distributed ICTs truly undo totalitarian governments, make impossible the concentration of finance capital and its domination over almost the entire world, or draw input from democratic polities in a way that seems structurally different from prior methods, or distribution of technology to the poor and disenfranchised helps them to attain self-sufficiency without sacrificing their own self-understanding in the process.

The advent of ICTs presents challenges and opportunities within every sphere of human activity; the advertisement of its opportunities often masks the challenges ICTs pose with its other hand while we aren't looking. The world is already networked and the world will never be networked; we are powerful actors in the network and we are dwarfed by the oligopolies that mange too much of it. We have never before had a major leader of innovation use "Don't Be Evil" as a regulative ideal in the Kantian sense, despite the suspicion that many of us have that such an ideal can largely be realized only in the breach. At another panel someone asked: "If Google is evil, what should replace it?". Maybe something better, but maybe something worse.

I saw this challenge as profoundly reciprocal, and here was something really new, and to my mind inspiring. I heard the vague presence of Google, Microsoft and Yahoo (and a few representatives of their general mindset among the attendees) saying: "if your methods really have anything for us, show us". And I heard us saying back: "if this 'revolution' really is for the good, show us". Both sides, I think, were serious in their message for the other. In this sense, I heard a call to responsibility to those of us from the world of critical studies of ICTs: we need to push even harder on all the fronts we have opened; we need to keep working to develop protocols that pull society toward its own ethical sense of itself; we need to keep standing and working outside of protocols, making outrageous accusations, worrying about catastrophes that may never happen. In this global call to bring our political and ethical insights into direct contact with the object of our critique, both socially and technologically, something really may be different this time - and it is up to us, maybe especially the people in that room and the people not there many of us were trying to keep in our minds - to bring that promise into being.

\section{References}

Fuchs, C. (2009). Conference Report: The Internet as Playground and Factory. tripleC, 7(2), 399-400.

\section{Conference links}

Conference web site: http://www. digitallabor.org

Twitter: http://twitter.com/idctweets

Conference Twitter hashtag: \#IPF09

Flickr: http://www.flickr.com/photos/newschool/collections/72157600533401886/ 
Vimeo: http://vimeo.com/user2103510/videos/sort:date

Conference video streams: http://streamingculture.parsons.edu/

Mailing list: http://digitallabor.org/discussion 